\title{
PENATALAKSANAAN FISIOTERAPI UNTUK MENGURANGI VERTIGO PADA PENDERITA BENIGN PAROXYSMAL POSITIONAL VERTIGO (BPPV) DENGAN TEKNIK SEMONT LIBERATORY MANEUVER DI KELURAHAN SUNGAI ANDAI KOTA BANJARMASIN
}

\section{(Management of Physiotherapy to Reduce Vertigo in Patient with Benign Paroxysmal Positional Vertigo (BPPV) using Semont Liberatory Maneuver in Kelurahan Sungai Andai of Banjarmasin City)}

\author{
Mu'jizatillah, Addini Nurul Risa, Enny Fauziah \\ Program Studi DIII Fisioterapi \\ Politeknik Unggulan Kalimantan \\ Email: mujizatillah@polanka.ac.id
}

\begin{abstract}
Benign Paroxysmal Positional Vertigo (BPPV) is a vestibular disorder that often caused vertigo. BPPV can be described as vertigo that occurred due to sudden changes in head position. Semont Liberatory Maneuver could reduce vertigo in BPPV. Semont Liberatory Maneuver aimed to move otolith from sensitive area of the ear to reduce the symptoms of vertigo. The purpose of this study was to determine the management of physiotherapy using Semont Liberatory Maneuver in reducing vertigo in patients with $B P P V$. This study used case study method with a single sample with vertigo symptom scale-short form as the measuring tool. The results of this study found semont liberatory maneuver that given for 8 times in 8 consecutive days with 4 times repetition for 15 minutes can reduce vertigo in patients with BPPV. Suggestions for researchers in the future to find out other effects of semont liberatory maneuver other then to reduce the frequency of vertigo in patients with BPPV.
\end{abstract}

Keywords: Vertigo, BPPV, Semont Liberatory Maneuver

\begin{abstract}
ABSTRAK
Benign Paroxysmal Positional Vertigo (BPPV) adalah gangguan vestibular yang paling sering menyebabkan vertigo. BPPV dapat diartikan sebagai vertigo yang terjadi akibat perubahan posisi kepala secara tiba-tiba. Semont Liberatory Maneuver dapat mengurangi vertigo pada BBPV. Semont Liberatory Maneuver bertujuan untuk memindahkan otolit dari dalam area sensitif telinga sehingga dapat mengurangi gejala vertigo. Tujuan dari penelitian ini adalah untuk mengetahui penatalaksanaan fisioterapi menggunakan Semont Liberatory Maneuver dalam mengurangi vertigo terhadap penderita BPPV. Penelitian ini menggunakan metode case study dengan sampel tunggal dengan alat ukur vertigo symptom scale-short form (VSS-sf). Dari hasil penelitian didapatkan hasil semont liberatory maneuver yang dilakukan sebanyak 8 kali selama 8 hari berturut-turut dengan intensitas $4 x$ pengulangan selama 15 menit dapat menurunkan vertigo pada kondisi BPPV. Saran kepada peneliti selanjutnya untuk
\end{abstract}


mencari tahu efek lain dari semont liberatory maneuver selain untuk menurunkan frekuensi vertigo pada BPPV.

Kata kunci: Vertigo, BPPV, Semont Liberatory Maneuver

\section{PENDAHULUAN}

Pusing merupakan salah satu keluhan yang sering dialami masyarakat sehari-hari. Salah satu penyebab pusing adalah vertigo. Vertigo dapat didefinisikan sebagai sensasi ilusi dari gerakan tubuh dan lingkungan sekitar (Alyono, 2018). Vertigo terbagi menjadi dua, yaitu vertigo perifer dan vertigo sentral. Salah satu bagian dari vertigo perifer adalah Benign Paroxysmal Positional Vertigo (BPPV). Menurut Grill et al. (2013), BPPV adalah gangguan vestibular yang paling sering menyebabkan vertigo. BPPV dapat diartikan sebagai vertigo yang terjadi akibat perubahan posisi kepala secara tiba-tiba (Hain, 2019).

Purnamasari (2010) menyatakan 5,6 miliar orang berkunjung ke rumah sakit dan klinik di Amerika Serikat dengan keluhan pusing. Diantara 5,6 juta orang tersebut, 17\% - 42\% didiagnosa menderita BPPV. Di Indonesia, menurut penelitian Adelia pada tahun 2012 sampai 2013 di RSUP H. Adam Malik Medan, prevalensi pasien dengan keluhan BPPV di Indonesia adalah 21,2\% pada tahun 2012 dan mengalami peningkatan pada tahun 2013 sebanyak 78,8\%. Pasien dengan rentang usia 41 tahun sampai 60 tahun memiliki prevalensi keluhan BPPV paling banyak, yaitu sebanyak 51,5\%. Di Banjarmasin, berdasarkan data rekam medis RSUD dr. H. M. Ansari Saleh pada tahun 2016 hingga 2019, terdapat 38 pasien rawat inap dan 118 pasien rawat jalan yang didiagnosa terkena BPPV.

BPPV ditandai dengan gejala vertigo, pusing, rasa seperti melayang, dunia seperti berjungkir balik, pening, dan sempoyongan. Gejala vertigo yang dialami penderita BPPV disebabkan oleh otokonia atau otolit yang terdiri dari kalsium karbonat yang terkumpul di dalam salah satu bagian dalam telinga yang bukan merupakan tempat semestinya (Hain, 2019). Hal ini menyebabkan daerah dengan penumpukkan otolit menjadi lebih sensitif terhadap perubahan gerak kepala, sehingga dapat menyebabkan gejala vertigo (Adelia, 2013).

Vertigo biasanya dideskripsikan sebagai rasa ingin pingsan, ketidakstabilan berjalan, kehilangan keseimbangan, persepsi terhadap rotasi, dan kecemasan (Grill et al., 2013). Vertigo dapat menyebabkan dampak negatif pada aktivitas sehari-hari, seperti pekerjaan, rekreasi, dan kegiatan sosial (Bronstein et al., 2010). Salah satu cara untuk mengurangi vertigo dapat dengan fisioterapi menggunakan modalitas berupa terapi latihan yang disebut semont liberatory maneuver.

Berdasarkan penelitian yang dilakukan oleh Kumar et al. (2014), semont liberatory maneuver dapat mengurangi vertigo pada BBPV. Semont liberatory maneuver bertujuan untuk memindahkan otolit dari dalam area sensitif telinga sehingga dapat mengurangi gejala vertigo. Zhang et al. (2017) membuktikan semont liberatory maneuver memiliki persentase kesembuhan untuk vertigo pada BPPV sebanyak 90,3\% setelah dilakukan terapi sebanyak 4 kali. Selain itu, dibuktikan juga bahwa setelah 90 hari dilakukannya semont liberatory maneuver, terjadi penurunan gejala vertigo yang signifikan pada BPPV. Namun, semont liberatory maneuver ini belum pernah digunakan dalam menangani vertigo pada BPPV di Kalimantan Selatan. Berdasarkan hal tersebut, penulis tertarik untuk meneliti penatalaksanaan fisioterapi untuk mengurangi vertigo pada penderita BPPV menggunakan teknik semont liberatory maneuver. 
ISSN 2656-7733

jurnal.polanka.ac.id/index.php/JKIKT

Volume 3 No. 1 (April, 2021)

\section{METODE PENELITIAN}

Jenis penelitian ini merupakan penelitian studi kasus (case study). Penelitian telah dilaksanakan di Kelurahan Sungai Andai Kota Banjarmasin. Penelitian dilakukan dari tanggal 10 April 2020 sampai 18 April 2020. Hasil penelitian dilaporkan pada bulan Juni 2020. Data penelitian diperoleh melalui data primer dan sekunder. Data primer didapat dari pengukuran langsung pada pasien yang dijadikan sampel kasus menggunakan instrumen penelitian vertigo symptom scale-short form (VSS-sf). Pelaksanaan penelitian yang dilakukan adalah sebagai berikut:

1. Datang ke rumah pasien setiap hari selama 8 hari dengan pelaksanaan terapi selama \pm 15 menit.

2. Melakukan anamnesis dan pemeriksaan fisik. Beberapa pemeriksaan fisik yang dilakukan adalah:

a. Vital signs, untuk mengetahui kondisi pasien saat itu dan menentukan pertimbangan untuk pengulangan gerakan manuver yang dilakukan.

b. Dix-Hallpike Test, untuk megetahui jenis BPPV dan kanal semisirkular mana yang terkena.

c. Supine Roll Test, untuk megetahui jenis BPPV dan kanal semisirkular mana yang terkena.

3. Kemudian melakukan pengukuran frekuensi onset vertigo menggunakan vertigo symptom scale-short form (VSS-sf) sebagai pre test sebelum terapi dilakukan.

4. Lalu melakukan intervensi berupa semont liberatoty manuever yang dilakukan sebanyak 4 kali pengulangan selama 15 menit.

5. Melakukan pemeriksaan vital signs untuk mengetahui keadaan pasien setelah intervensi dilakukan.

6. Melakukan pengukuran menggunakan vertigo symptom scale-short form (VSS-sf) sebagai post test untuk mengetahui evaluasi dari pemberian semont liberatory maneuver.

\section{HASIL DAN PEMBAHASAN}

Pasien atas nama $\mathrm{Ny}$. $\mathrm{H}$ usia 70 tahun dengan kondisi gangguan vertigo akibat BPPV. Sekitar 2 tahun yang lalu pasien tiba-tiba mengeluhkan pusing saat bangun tidur suatu pagi. Pusing dirasakan setiap pasien berbaring ke arah kiri dan bangun dari posisi berbaring. Setelah dilakukan assessment fisioterapi didapatkan problematika fisioterapi adanya pusing yang dirasakan saat berbaring ke arah kiri dan bangun dari posisi berbaring, adanya nystagmus yang berlangsung kurang dari satu menit, adanya gangguan pada kanal semisirkular posterior sinistra, dan adanya gangguan keseimbangan. Berdasarkan problematika yang didapat, pasien kemudian mendapat penatalaksanaan fisioterapi berupa semont liberatory maneuver setiap hari selama 8 hari berturut-turut dari tanggal 10 April hingga 17 April 2020. Hasilnya digambarkan dalam gambar grafik berikut. 


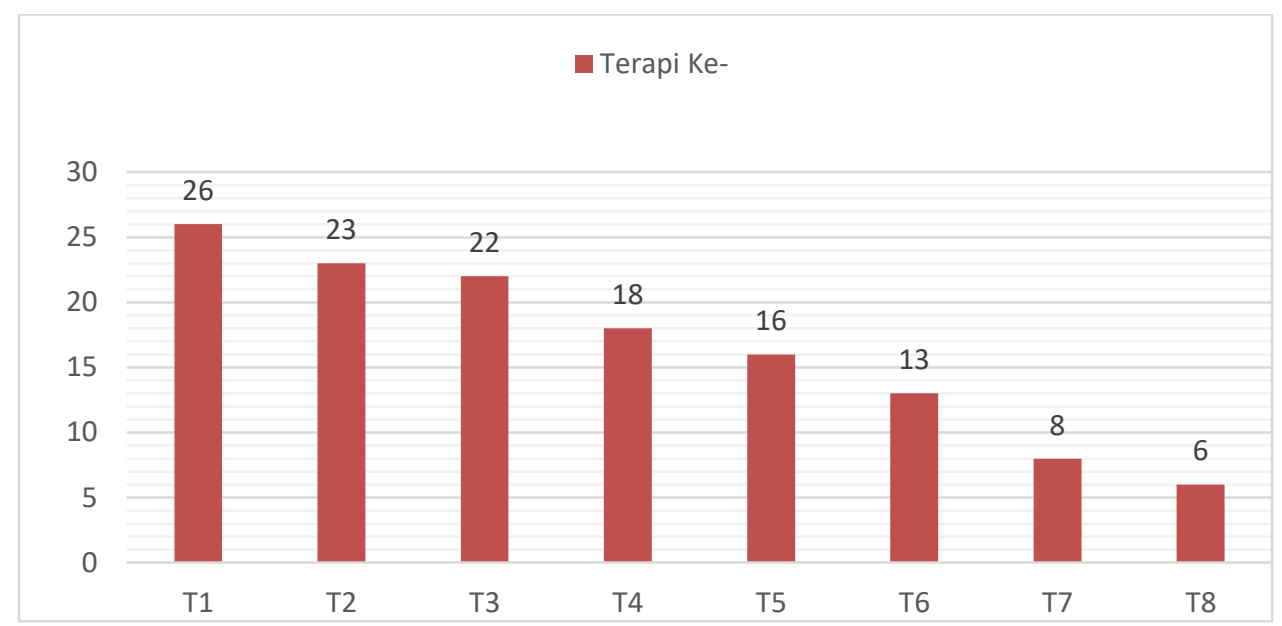

Gambar 1. Grafik Hasil Evaluasi Frekuensi Vertigo Menggunakan VSS-sf

Berdasarkan hasil dari data yang telah ditunjukkan dapat dilihat bahwa setelah dilakukan evaluasi selama 8 hari menggunakan VSS-sf terjadi penurunan pada frekuensi vertigo. Dengan begitu, modalitas fisioterapi semont liberatory maneuver yang digunakan dalam penatalaksanaan fisioterapi terhadap pasien yang mengalami vertigo akibat BPPV dapat menurunkan gejala vertigo.

BPPV disebabkan adanya debris yang berisi kalsium karbonat yang berasal dari otokonia. Debris tersebut terlepas dari makula yang terletak di uritkulus akibat proses degenerasi, sehingga menempel pada permukaan kupula yang terletak di kanal semisirkular posterior yang letaknya paling bawah (Sutarni, 2019). Hal tersebut menyebabkan daerah tersebut lebih berat dari pada cairan endolimfe di sekitarnya, sehingga menjadi sensitif terhadap sedikit perubahan arah gravitasi (Adelia, 2013).

Gerakan atau perubahan gravitasi pada kepala dan tubuh akan menimbulkan perpindahan cairan endolimfe di labirin dan silia. Rangsangan gerakan yang aneh dan berlebihan yang terjadi pada penderita BPPV akan mengganggu proses penyampaian impuls ke otak, sehingga respon penyesuaian mata, telinga, otot, dan sendi menjadi tidak adekuat sehingga muncul gerakan abnormal seperti vertigo dan nystagmus yang berlangsung sesaat (Kurniati, 2017).

Dalam keadaan lain, debris kalsium karbonat yang terlepas tidak melekat pada mukula, melainkan mengambang di dalam cairan endolimfe pada kanal semisirkular posterior. Ketika ada perubahan posisi kepala, debris bergerak di dalam kanal semisirkular menyebabkan cairan endolimfe bergerak dan menstimulasi ampula, sehingga menyebabkan onset vertigo (Sutarni, 2019). Semont liberatory maneuver adalah salah satu latihan yang dianjurkan untuk mengurangi vertigo pada BPPV (Mandalà et al., 2012).

Hal ini sesuai dengan penelitian yang dilakukan oleh Chen et al. (2012), yang menunjukkan bahwa semont liberatory maneuver dapat mengurangi vertigo pada BPPV. Selain itu, penelitian yang dilakukan Lee et al. (2014) menunjukkan semont liberatory maneuver selama 8 hari berturut-turut dapat mengurangi vertigo yang dialami oleh 32 partisipan. Studi lain yang dilakukan oleh Kumar et al. (2014) pada 30 partisipan yang mengalami vertigo akibat BPPV diberikan semont liberatory maneuver sebanyak 7 kali selama 7 hari berturut-turut didapatkan hasil adanya penurunan onset vertigo. 
Keluhan vertigo dapat berkurang dikarenakan semont liberatory maneuver mengeluarkan dan/atau memindahkan partikel kalsium karbonat yang mengapung bebas pada kanal semisirkular di mana partikel tersebut tidak seharusnya ada (Chen et al., 2012). Tahapan gerakan semont liberatory maneuver akan menguraikan gumpalan otokonia menjadi partikel yang lebih kecil, sehingga dapat keluar dari kanal semisirkular dan dapat menurunkan keluhan vertigo dan nystagmus (Zhang et al., 2017).

Pada anatomi sistem keseimbangan, kanal semisirkular dan vestibular yang berfungsi sebagai alat keseimbangan dan cochlea yang berfungsi sebagai pendengaran terletak di telinga bagian dalam. Sistem-sistem tersebut bekerja dengan cara menghubungkan saraf vestibulocochlearis dengan pusat vestibular yang terletak di otak dan sistem keseimbangan. Selain sistem vestibular, sistem propiosepsi yang terdiri dari sensor-sensor gerakan, posisi, dan tekanan yang berada pada otot, kulit, dan sendi berfungsi memberikan stimulus berupa sentuhan pada objek ruang yang sangat penting untuk menjaga posisi keseimbangan (Lee et al., 2014).

Dalam penelitian Chen et al. (2012), latihan semont liberatory maneuver dapat memaksimalkan kinerja tiga sistem yang berfungsi sebagai alat keseimbangan. Latihan semont liberatory maneuver berperan dalam meningkatkan efek adaptasi dan habituasi sistem vestibular. Pengulangan semont liberatory maneuver yang lebih sering akan berpengaruh dalam proses adaptasi pada tingkat integrasi sensorik, sehingga akan memberikan efek meningkatkan aliran darah ke otak untuk memperbaiki dan memaksimalkan kerja dari sistem sensorik, yaitu penglihatan (visual), sistem keseimbangan telinga dalam (vestibular), dan sistem sensori umum yang meliputi sensor gerak, tekanan, dan posisi. Hal tersebut dapat mengurangi respon stimuli berupa perasaan tidak nyaman dan sensasi berputar pada otak.

\section{KESIMPULAN}

Pemeriksaan fisioterapi yang dilakukan pada penderita vertigo akibat BPPV adalah dix-hallpike test, supine roll test, romberg test, tandem walking test, finger to nose test, serta vestibular disorders activities of daily living scale. Adapun diagnosa fisioterapi yang didapat pada penderita vertigo akibat BPPV adalah gangguan aktivitas fungsional karena pusing akibat vertigo et causa BPPV kanal semisirkular posterior sinistra sejak 2 tahun yang lalu.

Problematika fisioterapi yang didapat pada penderita vertigo akibat BPPV adalah pusing yang dirasakan setiap pasien berbaring ke arah kiri dan saat bangun dari posisi berbaring, nystagmus yang dirasakan kurang dari satu menit, gangguan pada kanal semisirkular posterior sinistra dan gangguan keseimbangan.

Intervensi fisioterapi yang dapat diberikan pada penderita vertigo akibat BPPV salah satunya adalah semont liberatory maneuver yang dilakukan sebanyak 8 kali selama 8 hari berturut-turut. Hasil yang didapat setelah melakukan evaluasi menggunakan VSSsf adalah terjadi penurunan frekuensi vertigo pada penderita BPPV.

\section{DAFTAR PUSTAKA}

Adelia, W. L. (2013). Karakteristik Pasien Penderita BPPV di RSUP H. Adam Malik Medan pada Tahun 2012-2013. Skripsi. Medan: Universitas Sumatera Utara.

Alyono, J. C. (2018). Vertigo and Dizziness: Understanding and Managing Fall Risk. Otolaryngologic Clinics of North America, 51(4), 725-740. 
Bronstein, A. M., Golding, J. F., Gresty, M. A., Mandala, M., Nuti, D., Shetye, A., \& Silove, Y. (2010). The social impact of dizziness in London and Siena. Journal of Neurology, 257(2), 183-190.

Chen, Y., Zhuang, J., Zhang, L., Li, Y., Jin, Z., Zhao, Z., Zhao, Y., \& Zhou, H. (2012). Short-term efficacy of semont maneuver for benign paroxysmal positional vertigo: A double-blind randomized trial. Otology and Neurotology, 33(7), 1127-1130.

Grill, E., Muller, M., Brandt, T., \& Jahn, K. (2013). Vertigo and dizziness: challenges for epidemiological research. OA Epidemiology, 1(2), 1-6.

Hain, T. C. (2019). Benign Paroxysmal Positional Vertigo (BPPV). Vestibular Disorder Association, 1-10.

Kumar, A. K., Kumar, K. S., Hari Babu, G., \& Keertana. (2014). The Effectiveness of Semont Liberatory Maneuver in Acute Beningn Paroxysmal Positional Vertigo Patients. International Journal of Physiotherapy, 1(3), 112-115.

Kurniati. (2017). Perbedaan Pengaruh Brandt Daroff dan Manuever Epley Terhadap Peningkatan Fungsional Vertigo. Skripsi. Yogyakarta: Universitas 'Aisyiyah Yogyakarta.

Lee, J. D., Shim, D. B., Park, H. J., Song, C. II, Kim, M. B., Kim, C. H., Byun, J. Y., Hong, S. K., Kim, T. S., Park, K. H., Seo, J. H., Shim, B. S., Lee, J. H., Lim, H. W., \& Jeon, E. J. (2014). A multicenter randomized double-blind study: Comparison of the Epley, Semont, and Sham maneuvers for the treatment of posterior canal benign paroxysmal positional vertigo. Audiology and Neurotology, 19(5), 336-341.

Mandala, M., Santoro, G. P., Libonati, G. A., Casani, A. Pietro, Faralli, M., Giannoni, B., Gufoni, M., Marcelli, V., Marchetti, P., Pepponi, E., Vannucchi, P., \& Nuti, D. (2012). Double-blind randomized trial on short-term efficacy of the Semont maneuver for the treatment of posterior canal benign paroxysmal positional vertigo. Journal of Neurology, 259(5), 882-885.

Purnamasari, P. (2010). Diagnosis dan Tata Laksana Benign Paroxysmal Positional Vertigo (BPPV). Bagian IImu Penyakit Saraf Universitas Udayana Denpasar, 124.

Sutarni, S., Malueka, R. G., Gofir. A. (2019). Bunga Rampai Vertigo. Yogyakarta: Gadjah Mada University Press.

Zhang, X., Qian, X., Lu, L., Chen, J., Liu, J., Lin, C., \& Gao, X. (2017). Effects of Semont maneuver on benign paroxysmal positional vertigo: a meta-analysis. Acta Oto-Laryngologica, 137(1), 63-70. 